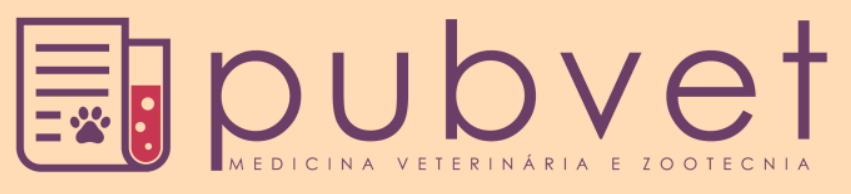

ISSN $1982-1263$

https://doi.org/10.22256/pubvet.v12n5a82.1-10

\title{
Fatores relacionados ao desenvolvimento reprodutivo em novilhas Nelore: Revisão
}

\author{
Rafael Teixeira de Sousa ${ }^{\ominus 1 *}$, Juliete de Lima Gonçalves ${ }^{\ominus 2}$, Sueli Freitas dos $\operatorname{Santos}^{\bullet} 3$, \\ Antonio Marcos Ferreira Fernandes ${ }^{\bullet}$, Gisele Dela Ricci ${ }^{\bullet} 5$ \\ ${ }^{I}$ Doutor em Nutrição e Produção Animal, Faculdade de Medicina Veterinária e Zootecnia, Universidade de São Paulo, Pirassununga, São \\ Paulo. E-mail: rafaelvnp@usp.br. *Autor para correspondência. \\ ${ }^{2}$ Doutoranda em Zootecnia, Universidade Federal da Paraíba, Areia, Paraíba. E-mail: julietegoncalves@gmail.com. \\ ${ }^{3}$ Doutora em Zootecnia, Universidade Federal do Ceará, Fortaleza, Ceará. E-mail: sfsantoszootecnia@gmail.com \\ ${ }^{4}$ Mestre em Zootecnia, Universidade Estadual Vale do Acaraú, Sobral, Ceará. E-mail: mascosff90@gmail.com \\ ${ }^{5}$ Doutoranda em Zootecnia, Faculdade de Zootecnia e Engenharia de Alimentos, Universidade de São Paulo, Pirassununga, São Paulo.E-mail: giseledelaricci@usp.br
}

RESUMO. A intensificação dos sistemas de produção de bovinos de corte, visando o aumento dos índices produtivos, exige a utilização de tecnologias que favoreçam a exploração racional da pecuária. Dentre os indicadores zootécnicos a eficiência reprodutiva destaca-se por estar intimamente associada as condições de nutrição, manejo e sanidade, que, juntamente com o padrão genético influenciam o desfrute geral do rebanho. Dentre as raças zebuínas Bos taurus indicus utilizadas nos sistemas de produção de carne do Brasil, a raça Nelore ocupa lugar de destaque, principalmente pela adaptação ao clima tropical. Entretanto, animais deste grupo genético, costumam ser sexualmente mais tardios que os de raças taurinas Bos taurus taurus, mesmo quando criados em condições semelhantes. E dentro desse contexto a idade ao primeiro parto é um dos aspectos que refletem diretamente na determinação da eficiência reprodutiva do rebanho. Partindo desse pressuposto, a inclusão de novilhas em idades mais jovens a reprodução, propiciando melhorias na lucratividade. Essa revisão tem como objetivo abordar alguns aspectos relacionados ao desenvolvimento reprodutivo em novilhas Nelore, tais como influência do peso vivo, nutrição, hormonioterapia e morfologia do trato reprodutivo. E de acordo com levantamento bibliográfico apresentado nessa revisão, conclui-se que a obtenção da puberdade em novilhas Nelore é de ordem multifatorial e varia em função do manejo geral do rebanho e da composição genética dos animais. Sendo importante salientar que a genética, peso vivo, nutrição e o manejo reprodutivo estão intimamente relacionados à idade a puberdade e ao primeiro parto.

Palavras chave: Bos taurus indicus, estradiol, progesterona

\section{Factors related to reproductive development in Nellore heifers: Review}

ABSTRACT. The intensification of beef cattle production systems, aiming to increase
production rates, requires the use of technologies that favor the rational exploitation of
livestock. Among the animal indicators, reproductive efficiency stands out because it is
closely associated with the conditions of nutrition, management and sanity, which together
with the genetic pattern influence the general enjoyment of the herd. Among the Bos taurus
indicus zebu breeds used in Brazilian meat production systems, the Nellore breed occupies
a prominent place, mainly due to its adaptation to the tropical climate. However, animals
of this genetic group are usually sexually late than those of Bos taurus taurus bulls, even
when bred in similar conditions. And within this context the age at first calving is one of 
the aspects that directly reflect the determination of the reproductive efficiency of the herd. Based on this assumption, the inclusion of heifers at younger ages to reproduction, providing improvements in profitability. This review aims to address some aspects related to reproductive development in Nellore heifers, such as the influence of live weight, nutrition, hormone therapy and reproductive tract morphology. According to a bibliographical survey presented in this review, it is concluded that the attainment of puberty in Nellore heifers is multifactorial and varies according to the general management of the herd and the genetic composition of the animals.

Keywords: Bos taurus indicus, estradiol, progesterone

\section{Factores relacionados con el desarrollo reproductivo en las novillas Nelore: Revisión}

RESUMEN. La intensificación de los sistemas de producción de bovinos de corte, visando el aumento de los índices productivos, exige la utilización de tecnologías que favorezcan la explotación racional de la ganadería. Entre los indicadores zootécnicos la eficiencia reproductiva se destaca por estar íntimamente asociada a las condiciones de nutrición, manejo y sanidad, que, junto con el patrón genético influencian el disfrute general del rebaño. Entre los Bos taurus indicus utilizados en los sistemas de producción de carne de Brasil, la raza Nelore ocupa un lugar destacado, principalmente por la adaptación al clima tropical. Sin embargo, los animales de este grupo genético, suelen ser sexualmente más tardíos que los de razas taurinas Bos taurus taurus, incluso cuando se crían en condiciones similares. Y dentro de ese contexto la edad al primer parto es uno de los aspectos que reflejan directamente la determinación de la eficiencia reproductiva del rebaño. A partir de ese presupuesto, la inclusión de novillas en edades más jóvenes a reproducción, propiciando mejoras en la rentabilidad. Esta revisión tiene como objetivo abordar algunos aspectos relacionados al desarrollo reproductivo en novillas Nelore, tales como influencia del peso vivo, nutrición, hormonoterapia y morfología del tracto reproductivo. Y de acuerdo con el levantamiento bibliográfico presentado en esa revisión, se concluye que la obtención de la pubertad en novillas Nelore es de orden multifactorial y varía en función del manejo general del rebaño y de la composición genética de los animales. Es importante señalar que la genética, el peso vivo, la nutrición y el manejo reproductivo están íntimamente relacionados con la edad a la pubertad y al primer parto.

Palabras clave: Bos taurus indicus, estradiol, progesterona

\section{Introdução}

A raça Nelore ocupa lugar de destaque entre as raças utilizadas nos sistemas de produção de carne do Brasil, principalmente pela adaptação ao clima tropical. Entretanto, animais deste grupo genético, costumam ser sexualmente mais tardios que os de raças taurinas Bos taurus taurus, mesmo quando criados em condições semelhantes (Rodrigues et al., 2002).

$\mathrm{O}$ atraso na vida reprodutiva das matrizes tem como consequências o aumento no rebanho de fêmeas que não estão em reprodução, redução na taxa de desfrute e eficiência de produção de bezerros, diminuindo o lucro da atividade e atrasando o processo de seleção genética. A melhoria no desempenho reprodutivo, por meio da redução na idade ao primeiro parto (IPP) das fêmeas exerce impacto significativo sobre os indicadores produtivos do rebanho. Em bovinos, o desenvolvimento do sistema reprodutivo pós-natal é marcado primeiramente por um aumento no crescimento de todo o trato reprodutivo entre $3 \mathrm{e}$ 4 meses de idade, seguido por um período de crescimento lento e por uma fase de crescimento acelerado próxima a primeira ovulação. Estas diferenças no desenvolvimento são consequências da variação na concentração de gonadotrofinas que aceleram a proliferação folicular e a produção de estradiol determinando a variação na velocidade de crescimento dos órgãos reprodutivos em diferentes períodos (Honaramooz et al., 1999, Day et al., 2010).

A idade ao primeiro parto é um dos aspectos que refletem diretamente na determinação da eficiência reprodutiva dos rebanhos, tendo grande influência no número de bezerros produzidos 
durante toda a vida produtiva da futura vaca (Machado et al., 2001, Stygar et al., 2014). E partindo desse pressuposto, a inclusão de novilhas em idades mais jovens a reprodução, pode aumentar a taxa de desfrute na propriedade (Zervoudakis et al., 2002). Ao se reduzir o custo com a exclusão de um ano de recria aumenta-se 0,5 a 0,8 bezerros por vaca durante a sua vida produtiva (Eler et al., 2002).

\section{Puberdade em fêmeas bovinas}

A puberdade é considerada um importante indicador econômico na pecuária de corte. Dentro da fisiologia reprodutiva de fêmeas, a puberdade pode ser definida como o início da atividade reprodutiva, que é marcada por alterações na concentração de gonadotrofinas e pelo aumento dos hormônios esteroides sexuais circulantes, envolvendo um complexo processo fisiológico e molecular (Honaramooz et al., 1999). O período correspondente aos 40-60 dias prévios a primeira ovulação é designada como pré-puberdade (Pereira et al., 2010, Day et al., 2010). Esta fase envolve a transição de um período de inatividade ovarina para outro, no qual ocorre o estágio final da maturação do eixo hipotalâmico-hipofisáriogonadal e início das ovulações (Moran et al., 1989).

O acasalamento logo após o primeiro estro seguido de ovulação não é aconselhado, já que a fertilidade nesse período tem sido reportada como baixa, principalmente, pela ocorrência de um ciclo estral curto associado a luteólise prematura do corpo lúteo entre o $8^{\circ}$ e $12^{\circ}$ dias (Yavas \& Walton, 2000) resultando em concentração sérica de progesterona menor que $1,0 \mathrm{ng} / \mathrm{ml}$ no dia 9 do ciclo (Sá Filho et al., 2007), o que impede a manutenção da prenhez, já que o período crítico para o reconhecimento materno do embrião ocorre do $15^{\circ}$ ao $19^{\circ}$ dias (Giassetti et al., 2008). A maturação final do trato reprodutivo da futura matriz, resultante da exposição aos esteroides ovarianos, dos ciclos estrais posteriores a obtenção da puberdade (Sá Filho et al., 2007).

Dentre os hormônios envolvidos com a fisiologia da puberdade o LH é considerado o fator endócrino primário para que a novilha se torne púbere. E isso só é possível a partir da redução do feedback negativo exercido pelo estradiol (Couse \& Korach, 1999), fenômeno que é observado na fase pré-púbere. A secreção pulsátil de LH é estabelecida nas bezerras por volta de 1 a 2 meses de idade (Anderson et al., 1996) e aumenta por volta do $3^{\circ}$ e $5^{\circ}$ meses de idade (Schams et al., 1981). Subsequentemente, a secreção de LH diminui (Schams et al., 1981) e mantem-se relativamente baixa (fase estática) até um novo aumento da secreção de LH (fase pré-púbere) culminando em puberdade. Uma das causas do aumento na frequência de pulsos de LH na fase pré-púbere é consequência da menor sensibilidade do hipotálamo a retroalimentação negativa exercida pelo estradiol (Honaramooz et al., 1999, Day \& Anderson, 1998, Day et al., 2010) resultando em crescimento dos folículos antrais e aumento da produção de estradiol, seguido por uma elevação transitória na secreção de LH. Em novilhas, a concentração plasmática de estradiol permanece baixa até o período pré-puberal, quando aumenta gradualmente até o momento da primeira ovulação (Nakada et al., 2000).

Além das mudanças observadas no eixo hipotalâmico-hipofisário-gonadal durante o período que antecede a puberdade os órgãos sexuais, também passam por alterações morfofisiológicas, propiciando condições adequadas para o estabelecimento da prenhez, dentre as alterações relatadas, estão: o aumento no peso do útero, cérvix e vagina, sendo que novilhas pré-púberes geralmente possuem diâmetro do útero inferior em relação as novilhas púberes (Desjardins \& Hafs, 1969, Honaramooz et al., 1999)

\section{Relação entre peso vivo, nutrição e puberdade}

Os mecanismos da atuação dos fatores nutricionais sobre o desencadeamento da puberdade são múltiplos, podendo ocorrer várias interações entre a disponibilidade dos nutrientes, com o genótipo, peso, escore de condição corporal, idade e composição corporal dos animais (Collier et al., 2006, Robinson et al., 2006). O conhecimento do peso vivo e composição corporal das novilhas a puberdade é fundamental para a definição do sistema de criação das mesmas, uma vez que determinam o ganho de peso necessário durante a fase pré-púbere. E apesar da importância do peso vivo e composição corporal à puberdade, existe uma falta de consenso devido a variação nos resultados experimentais referentes os efeitos dessas características na raça Nelore (Silva et al., 2009). Em países com pecuária mais produtiva, o manejo seletivo visa à entrada das novilhas em estação de monta aos 15 meses, resultando em IPP de 24 meses e produtividade máxima (Wolfe et al., 1990, Patterson et al., 1992). Em uma metanálise de dados brasileiros realizada por Silva et al. 
(2009) em que foram utilizados dados de novilhas Nelore criadas em condições brasileiras foi verificado que as novilhas dessa raça atingiram a puberdade com $312 \mathrm{~kg}$ de peso vivo (PV) e 22 meses de idade, enquanto que novilhas cruzadas atingiram a puberdade com $289 \mathrm{~kg}$ e 14 meses de idade. Resultados encontrados para a raça Nelore têm demostrado altos coeficientes de herdabilidade $\left(\mathrm{h}^{2}\right)$ que variam de 0,57 (Eler et al., 2002) a 0,73 (Silva et al., 2003) para prenhez aos 14 meses e 0,52 para prenhez aos 16 meses (Dias et al., 2004). Esse alto coeficiente de herdabilidade para prenhez aos 14 meses de idade sugere um grande potencial de seleção para esta característica nessa raça (Eler et al., 2002).

Embora os dados de literatura tenham dado pouca ênfase, o ganho de peso logo após o desmame tem se demonstrado como um relevante fator no desencadeamento da puberdade em novilhas, em que maiores ganhos de peso nessa fase resultam em menores idades à puberdade. $\mathrm{O}$ fornecimento de dietas com alta densidade energética após o desmame aos $73 \pm 3$ dias de idade, ativou precocemente o eixo reprodutivo de bezerras cruzadas Aberdeen Angus x Simental, resultando em puberdade antes dos 300 dias de idade (Gasser et al., 2006).

Inúmeras teorias foram desenvolvidas na tentativa de explicar como o status nutricional influencia o desencadeamento da puberdade. Em 1974, Frisch \& McArthur (1974) propuseram, então, a hipótese de que uma quantidade mínima de gordura corporal seria necessária para a ocorrência normal da menarca em adolescentes e da menstruação normal nas mulheres. Entretanto a teoria da "porcentagem mínima de gordura", ainda é controversa. Estudos realizados com ratos (Bronson, 1987) e com novilhas (Brooks et al., 1985) demostraram que a puberdade não está relacionada com uma porcentagem constante de gordura corporal. Desta forma é improvável que o tecido adiposo, por si só, seja o elo entre o status nutricional e secreção de LH. O mais provável é que numerosos mecanismos estejam envolvidos e que alterações metabólicas decorrentes das flutuações nutricionais, com consequente alteração na gordura corporal, regulem a liberação pulsátil de LH. Os mecanismos pelos quais os estímulos nutricionais e sinais metabólicos afetam o sistema nervoso central e modulam a frequência da liberação dos pulsos de LH pela hipófise anterior têm sido extensivamente estudados. E a relação entre a nutrição e o $\mathrm{LH}$ pode ocorrer através de sinais sanguíneos específicos, como metabólitos e hormônios metabólicos (Steiner et al., 1983), dentre eles pode-se citar o fator de crescimento semelhante à insulina do tipo I (IGF1), a insulina, a glicose, a leptina e o neuropeptídio Y. As concentrações do IGF-1 produzido pelo fígado e pelas células da granulosa possuem alta correlação (Webb (Webb et al., 2004, Webb et al., 2003) e o aumento deste metabólito no período peripuberal tem a capacidade de acelerar a puberdade, por promover elevação nas concentrações intrafoliculares de estradiol (Jones et al., 1991, Yelich et al., 1996).

Além da conhecida ação do IGF-1 a nível de células foliculares, foi demostrado em um estudo realizado com ratos por Hiney et al. (1996) que este hormônio também acelera a puberdade via sistema nervoso central (eminência média), promovendo o aumento da liberação de GnRH que por sua vez estimula o aumento da frequência dos pulsos de LH. Segundo os autores, a ação do IGF1 não é diretamente sobre os neurônios produtores de $\mathrm{GnRH}$, mais sim sobre as células da glia, que por sua vez, estimulam liberação de GnRH de forma indireta.

A glicose também tem a sua importância como mediador dos efeitos nutricionais no início e na manutenção da atividade reprodutiva em diversas espécies, inclusive na secreção de LH. Ovelhas submetidas à indução de hipoglicemia mediante a administração de insulina apresentaram um atraso na onda de LH; porém quando receberam uma infusão de glicose associada à insulina, os níveis glicêmicos e a secreção de LH foram normalizados (Medina et al., 1998).

Outro hormônio reportado em diversos estudos associado com a puberdade e maturidade sexual de novilhas é a leptina (Prolo et al., 1998), cuja a produção é regulada por alterações induzidas pela insulina e pelos glicocorticoides nos adipócitos, e suas concentrações se correlacionam com a quantidade de reserva corporal (Costa \& Duarte, 2006). A ação da leptina sobre a reprodução pode ocorrer de duas maneiras: de forma direta, quando age sobre as gônadas promovendo o aumento na produção de esteroides sexuais, o que foi evidenciado pelo aumento no tamanho uterino, em razão da maior proliferação glandular no epitélio e endométrio uterino; e de forma indireta, por meio da sua ação sobre o eixo hipotalâmicohipofisário-gonadal, cuja função é informar sobre o estado nutricional, permitindo que os mecanismos reprodutivos sigam em frente quando houver reservas energéticas suficientes para 
reprodução, caso contrário, este fenômeno é temporariamente bloqueado (Barash et al., 1996). Vaiciunas et al. (2008) reportaram que novilhas que entram em puberdade mais cedo, apresentam maior expressão de leptina pelos tecidos adiposos subcutâneo e omental quando comparadas as novilhas não púberes. Além da maior expressão de leptina no tecido adiposo esses pesquisadores reportaram uma menor expressão de genes hipotalâmicos que codificam receptores do neuropeptídeo-Y. Lebrethon et al. (2000) verificaram que os efeitos da leptina sobre a secreção de gonadotrofinas parecem ser mediados parcialmente pelo NPY, que inibe a secreção de LH, uma vez que o NPY está diretamente envolvido com os neurônios que secretam o GnRH, o qual está associado à liberação de LH pela hipófise. O NPY é um potente estimulador de consumo e inibidor da secreção de gonadotrofinas. Ao chegar ao hipotálamo, a leptina age, pelo menos, sobre dois tipos neurais situados no núcleo arqueado. No primeiro sítio, ela age reprimindo a produção do neuropeptídio Y (NPY), que é um poderoso estimulador do apetite; ao mesmo tempo, a leptina também reprime a produção do peptídeo relacionado ao agouti (AgRP) e que é um antagonista dos peptídeos anorexigênicos (MC4R e $\alpha \mathrm{MSH})$, que inibem a ingestão de alimentos. Em outro grupo de neurônios do núcleo arqueado, segundo sítio de ação, a leptina estimula a produção dos compostos da proopiomelanocotina (POMC), como o $\alpha \mathrm{MSH}$, e a produção do transcrito regulado pela cocaína e anfetamina (CART), que são responsáveis pela inibição do apetite.

Como evidenciado nesse tópico, a nutrição possui um papel fundamental em relação ao início da atividade cíclica, particularmente em novilhas, e situações de sub ou superalimentação devem ser evitadas (Patterson et al., 1992). O aporte nutricional e o ganho de peso adequado são responsáveis pela ativação e manutenção ciclos estrais normais nessa categorial animal. Ao objetivar a antecipação da idade ao acasalamento de novilhas, deve-se buscar maior ganho de peso visando maiores taxas de prenhez (Barcellos et al., 2006).

\section{Hormonioterapia e puberdade}

A hormonioterapia quando bem aplicada, pode melhorar substancialmente a eficiência reprodutiva de novilhas. Atualmente existe uma infinidade de protocolos utilizados na obtenção de diferentes respostas dentro da fisiologia reprodutiva de fêmeas. No que tange a indução de puberdade em novilhas, a administração de progesterona ou progestágenos em associação ou não a outros hormônios tem sido bastante utilizada (Lamb et al., 2006, Tauck et al., 2007).

A habilidade dos progestágenos na indução da puberdade está relacionada primariamente à maturidade do sistema neuroendócrino e a via de regulação da secreção de LH. Esse mecanismo se dá pela da redução da expressão dos receptores hipotalâmicos de estradiol e do feedback negativo exercido pelo o mesmo nos neurônios secretores de GnRH (Day \& Anderson, 1998). Desse modo, a gradativa redução da sensibilidade do hipotálamo aos efeitos inibitórios do estradiol, propicia um aumento na frequência de liberação dos pulsos de LH (Marson et al., 2004). Essa redução do feedback negativo ao estradiol, ocorre pela diminuição na concentração de seus receptores citoplasmáticos na porção anterior do hipotálamo, no hipotálamo médiobasal e na hipófise anterior (Day et al., 1987, Kinder et al., 1987, Kinder et al., 1995).

A presença de estradiol modula genes relacionados ao controle metabólico do hipotálamo anterior, afetando direta ou indiretamente os neurônios GnRH. Contudo, a eficácia da hormonioterapia é dependente de outros fatores como o manejo nutricional, genótipo, idade e peso da novilha no momento da aplicação dos fármacos (Azeredo et al., 2007). Outro viés importante na indução de puberdade por progesterona está relacionado ao efeito dose e tempo de exposição ao hormônio, principalmente no caso de novilhas zebuínas, já que esses animais apresentam uma menor taxa metabólica quando comparados a animais taurinos, assim o emprego de altas doses de progesterona nessas novilhas pode levar a uma diminuição da pulsatilidade de $\mathrm{LH}$, comprometendo o crescimento folicular, a ovulação (Baruselli et al., 2007, Prado et al., 2015), o estro e o pico pré-ovulatório de LH (Rawlings et al., 2003).

Nesse sentido Sá Filho et al. (2015) dosaram a concentração circulante de P4 em novilhas Nelore pré-púberes onde avaliaram a eficácia da utilização de $\mathrm{CIDR}^{{ }^{\circledR} \mathrm{S}}$ novos, ou usados previamente utilizado por 3 vezes durante 8 dias, denominados de $\mathrm{CIDR}^{\circledR} 4$ ( 24 dias de uso prévio) implantados intravaginalmente por 10 dias, em relação ao grupo sem implante intravaginal de liberação lenta de P4 (Controle). Foi verificado que ambos os dispositivos foram capazes de 
sustentar o nível de P4 acima de $1,0 \mathrm{ng} / \mathrm{ml}$ por no mínimo 7 dias, em relação ao grupo controle, entretanto os grupos que receberam os dispositivos intravaginais obtiveram maiores concentrações plasmáticas de $\mathrm{P} 4(\mathrm{P}>0,05)$. O que resultou em uma maior taxa de ovulação $(\mathrm{P}=0,04)$ nas novilhas submetidas aos $\mathrm{CIDR}^{{ }^{\circledR} \mathrm{S} \text { novos }}=30 \%$ (3/10), e usados $\operatorname{CIDR}^{\circledR} 4=55,6 \%$ (5/9) em relação ao grupo controle $=0,0 \%(0 / 8)$, demostrando a importância da utilização da P4 exógena na indução da ovulação em novilhas Nelore. Anderson et al. (1996) reportaram que a aplicação de implante de P4 durante nove dias foi suficiente para desencadear a puberdade em $81 \%$ das novilhas. Este fato foi associado ao aumento subsequente na liberação de LH em decorrência da aplicação de $\mathrm{P} 4$, promovendo maior desenvolvimento folicular, que consequentemente, aumentou a produção de E2, proporcionando maior desenvolvimento uterino. Durante o período de aplicação da progesterona foi reportado que ocorreu inibição da liberação de LH de forma semelhante ao que ocorre no ciclo estral de fêmeas maduras, evidenciando que os mecanismos relacionados a essa inibição já estão presentes em novilhas pré-púberes.

Pfeifer et al. (2009) avaliaram o efeito do programa curto de sincronização em novilhas Bos taurus taurus, com CIDR ${ }^{\circledR}$ por 5 dias, com ou sem prostaglandina $2 \alpha \quad$ (PGF2 $\alpha ; 500 \quad \mathrm{mg}$ de cloprostenol, i.m.) na retirada dos $\mathrm{CIDR}^{\Theta_{\mathrm{S}}}$, foi observado que os animais pertencentes ao grupo $\mathrm{CIDR}^{\circledR}+$ PGF $2 \alpha$ apresentaram maior taxa de ovulação $(72,7 \%$; $\mathrm{P}<0,01)$ em comparação aos animais tratados apenas com CIDR $^{\circledR}(30,8 \%)$ e o grupo controle, sem $\mathrm{CIDR}^{\circledR}(7,1 \%)$. Associado a esses resultados nenhuma das novilhas tratadas com CIDR $^{\circledR}$ apresentaram ciclo curto após a ovulação (P < 0,01). Claro Júnior et al. (2010) avaliando a eficácia de $\mathrm{CIDR}^{{ }^{\circledR}} \mathrm{S}$ novos ou usados $\mathrm{CIDR}^{\circledR} 4$ previamente utilizado por 3 vezes durante 9 dias (27 dias de uso) implantados intravaginalmente por 12 dias, para induzir a puberdade em 589 novilhas Nelore. Foi verificado aos 7 dias após a retirada do implante, as novilhas tratadas com CIDR ${ }^{\circledR}$, sejam eles novos ou usados, apresentaram maior incidência de estro $(\mathrm{P}>0,05$; $42,6 \%$ para o $\mathrm{CIDR}^{\circledR} 1$ e $39,3 \%$ para o $\left.\mathrm{CIDR}^{\circledR} 4\right)$ em relação a taxa de $(19,5 \%$ do grupo controle; composto por novilhas que não receberam implante de P4, mas apenas PGF2 $\alpha$ no D0). Enquanto que a taxa de prenhez aos 90 dias (final da estação de monta) foi maior $(\mathrm{P}>0,05)$ no $\mathrm{CIDR}^{\circledR} 1(83,5 \%)$ e $\mathrm{CIDR}^{\circledR} 4(83,7 \%)$, que o grupo sem $\quad$ CIDR $^{\circledR} \quad(72,6 \%)$. Estes resultados demonstraram que a utilização do $\mathrm{CIDR}^{\circledR}$, previamente utilizado ou não, foi eficaz para acelerar a puberdade e aumentar a taxa de prenhez das novilhas. Outro dispositivo intravaginal de liberação lenta de P4 bastante utilizado em indução de puberdade em novilhas de corte é o Primer $^{\circledR}$. $\mathrm{O}$ uso do Primer ${ }^{\circledR}$ por durante 8 dias, associado a aplicação de $2 \mathrm{ml}$ e $1 \mathrm{ml}$ de RIC BE ${ }^{\circledR}$ (Benzoato de estradiol) nos dias da inserção e retirada do dispositivo, respectivamente, é capaz de acelerar a entrada da puberdade em novilhas pré-púberes por simular fisiologicamente, a produção de E2 pelo folículo e P4 pelo corpo lúteo. $\mathrm{O}$ aumento nas concentrações desses hormônios estimula o desenvolvimento endometrial, além do mais, o E2 atua na manifestação de estro e maturação das glândulas uterinas e mamárias (Manual Tecnopec, 2017).

\section{Morfologia do trato reprodutivo e puberdade}

Nos últimos anos, alguns estudos têm sido realizados, com o intuito de desenvolver técnicas e procedimento que favoreçam a entrada precoce de novilhas na reprodução. Dentre eles, os relacionados à organização morfológica dos tecidos do sistema reprodutor, e sua relação com as funções orgânicas, metabolismo e comportamento sexual da novilha tem merecido atenção especial. Os tecidos crescem e se desenvolvem cronologicamente em ondas de crescimento específicos e esses mesmos preceitos são aplicados para a maturidade. A onda de crescimento tecidual é iniciada com o tecido nervoso, seguido pelo tecido muscular e tecido adiposo. O desenvolvimento tecidual precoce, médio ou tardio varia de acordo com o tecido estudado e sua localização no corpo do animal (Owens et al., 1993). Como já mencionado, durante o período pós-natal, mecanismos endócrinos garantem que a bezerra não ative o sistema reprodutivo até que possua um desenvolvimento somático compatível com a reprodução, próximo de $65-70 \%$ do peso adulto. Ao atingir essa faixa de peso, ocorre uma sinalização do metabolismo energético do animal, que informa que o gasto energético com o crescimento e desenvolvimento estão diminuindo, tornando permissiva a utilização de energia pelos mecanismos relacionados à reprodução (Semmelmann et al., 2001). Paulatinamente, ocorre uma substituição da ação dos hormônios de crescimento pelos sexuais. E ao atingir a puberdade, o trato reprodutivo da novilha, passa 
por uma série de modificações no âmbito morfológico e fisiológico que irão permitir o estabelecimento de uma futura gestação e lactação (Desjardins \& Hafs, 1969).

Existe uma relação entre o desenvolvimento uterino de novilhas Nelore com a puberdade, e reportaram que o desenvolvimento do trato reprodutivo foi decorrente da estimulação exercida pelo aumento das concentrações de estradiol e progesterona durante o período póspúbere. $\mathrm{O}$ escore do trato reprodutivo tem sido uma das metodologias aplicadas na avaliação do estágio de desenvolvimento do trato reprodutivo de novilhas a campo, auxiliando na seleção de fêmeas destinadas a reprodução, e na projeção do desempenho das mesmas em programas de inseminação artificial em tempo fixo (IATF) (Andersen et al., 1991). Esse sistema utiliza uma escala de 1 a 5 , permitindo estimar a maturidade sexual com base na avaliação das estruturas ovarianas e desenvolvimento uterino, a nota um é dada a animais que apresentam trato reprodutivo infantil, caracterizado pela ausência de tônus uterino, ovários pequenos e sem estruturas palpáveis. Já as novilhas com escore de trato reprodutivo dois apresentam um maior diâmetro dos cornos uterinos e estruturas ovarianas em relação aos animais com a nota um. Novilhas com escore três estão bastante próximas de entrarem em puberdade, por apresentarem um bom tônus e desenvolvimento uterino e folículos ovarianos palpáveis. Animais com escore quatro apesar de não apresentarem tecido luteal facilmente perceptível, possuem indicativo de ciclicidade, que pode ser verificada pela observação do diâmetro uterino. Novilhas com escore do trato reprodutivo cinco apresentam características semelhantes aos animais com escore quatro, porém evidenciam a presença de um corpo lúteo (Andersen et al., 1991). As novilhas com escore um são consideradas impúberes, com escore dois e três pré-púberes, e com o escore quatro e cinco púberes (Patterson et al., 2000). Em um estudo realizado por Holm et al. (2008) foi reportado uma taxa de prenhez de $31,40,53,70$ e $80 \%$, respectivamente para escores de trato reprodutivo $1,2,3,4$ e 5 . Nesse sentido, antes de submeter as novilhas a reprodução é importante que se realize um exame ginecológico para a avaliação da condição uterina e ovariana. Sendo que os animais impúberes, com útero infantil e ovários poucos desenvolvidos, devem ser descartados da estação de monta.

\section{Considerações finais}

O surgimento da puberdade em novilhas Nelore tem origem multifatorial e varia em função do manejo geral do rebanho e da composição genética dos animais. Sendo importante salientar que a nutrição, genética, peso vivo, escore do trato reprodutivo e estão intimamente relacionados à idade a puberdade e ao primeiro parto. Ademais, a antecipação da puberdade por meio dos protocolos de indução de ciclicidade pode ser uma importante estratégia a ser adotada para melhorar os índices reprodutivos e produtivos do rebanho.

\section{Referências Bibliográficas}

Andersen, K. J., LeFever, D. G., Brinks, J. S. \& Odde, K. G. 1991. The use of reproductive tract scoring in beef heifers. Agri Practice, 12, 1926.

Anderson, L. H., McDowell, C. M. \& Day, M. L. 1996. Progestin-induced puberty and secretion of luteinizing hormone in heifers. Biology of Reproduction, 54, 1025-1031.

Azeredo, D. M., Rocha, D., Jobim, M. I. M., Mattos, R. C. \& Gregory, R. M. 2007. Efeito da sincronização e indução de estros em novilhas sobre a prenhez e o índice de repetição de crias na segunda estação reprodutiva. Ciência Rural, 37, 201-205.

Barash, I. A., Cheung, C. C., Weigle, D. S., Ren, H., Kabigting, E. B., Kuijper, J. L., Clifton, D. K. \& Steiner, R. A. 1996. Leptin is a metabolic signal to the reproductive system. Endocrinology, 137, 3144-3147.

Barcellos, L. J. G., Kreutz, L. C. \& Quevedo, R. M. 2006. Previous chronic stress does not alter the cortisol response to an additional acute stressor in jundiá (Rhamdia quelen, Quoy and Gaimard) fingerlings. Aquaculture, 253, 317321.

Baruselli, P. S., Gimenes, L. U. \& Sales, J. N. S. 2007. Fisiologia reprodutiva de fêmeas taurinas e zebuínas. Revista Brasileira de Reprodução Animal, 31, 205-211.

Bronson, F. H. 1987. Puberty in female rats: relative effect of exercise and food restriction. American Journal of Physiology-Regulatory, Integrative and Comparative Physiology, 252, R140-R144.

Brooks, A. L., Morrow, R. E. \& Youngquist, R. S. 1985. Body composition of beef heifers at puberty. Theriogenology, 24, 235-250. 
Claro Júnior, I., Sá Filho, O. G., Peres, R. F. G., Aono, F. H. S., Day, M. L. \& Vasconcelos, J. L. M. 2010. Reproductive performance of prepubertal Bos indicus heifers after progesterone-based treatments. Theriogenology, 74, 903-911.

Collier, R. J., Dahl, G. E. \& VanBaale, M. J. 2006. Major Advances Associated with Environmental Effects on Dairy Cattle. Journal of Dairy Science, 89, 1244-1253.

Costa, J. V. \& Duarte, J. S. 2006. Adipose tissue and adipokines. Acta medica Portuguesa, 19, 251-6.

Couse, J. F. \& Korach, K. S. 1999. Estrogen receptor null mice: what have we learned and where will they lead us? Endocrine Reviews, 20, 358-417.

Day, M. L. \& Anderson, L. H. 1998. Current concepts on the control of puberty in cattle. Journal of Animal Science, 76, 1-15.

Day, M. L., Gasser, C. L., Grum, D. E. \& Pires, A. V. 2010. Fatores que afetam a idade na puberdade em novilhas de corte. In: Pires, A. V. (ed.) Bovinocultura de corte. Fealq, Piracicaba, São Paulo.

Day, M. L., Imakawa, K., Wolfe, P. L., Kittok, R. J. \& Kinder, J. E. 1987. Endocrine mechanisms of puberty in heifers. Role of hypothalamopituitary estradiol receptors in the negative feedback of estradiol on luteinizing hormone secretion. Biology of Reproduction, 37, 10541065.

Desjardins, C. \& Hafs, H. D. 1969. Maturation of bovine female genitalia from birth through puberty. Journal of Animal Science, 28, 502507.

Dias, L. T., El Faro, L. \& Albuquerque, L. G. 2004. Estimativas de herdabilidade para idade ao primeiro parto de novilhas da raça Nelore. Revista Brasileira de Zootecnia, 33, 97-102.

Eler, J. P., Silva, J. A. I. I. V., Ferraz, J. B. S., Dias, F., Oliveira, H. N., Evans, J. L. \& Golden, B. L. 2002. Genetic evaluation of the probability of pregnancy at 14 months for Nellore heifers. Journal of Animal Science, 80, 951-954.

Frisch, R. E. \& McArthur, J. W. 1974. Menstrual cycles: fatness as a determinant of minimum weight for height necessary for their maintenance or onset. Science, 185, 949-951.

Gasser, C. L., Behlke, E. J., Grum, D. E. \& Day, M. L. 2006. Effect of timing of feeding a highconcentrate diet on growth and attainment of puberty in early-weaned heifers 1. Journal of Animal Science, 84, 3118-3122.

Giassetti, M. I., Pontes, E. O., Niemeyer, C., Siqueira, A. F. P., Fedozzi, F., Lima, M. C., Marques, V. B., Bertan, C. M., Miglino, M. A. \& Arruda, R. P. 2008. Quantificação do interferon-tau durante $\mathrm{o}$ reconhecimento materno da gestação em fêmeas bovinas Bos taurus indicus. Brazilian Journal of Veterinary Research and Animal Science, 45, 111-120.

Holm, D. E., Thompson, P. N. \& Irons, P. C. 2008. The economic effects of an estrus synchronization protocol using prostaglandin in beef heifers. Theriogenology, 70, 15071515.

Honaramooz, A., Chandolia, R. K., Beard, A. P. \& Rawlings, N. C. 1999. Effects of season of birth on the prepubertal pattern of gonadotropin secretion and age at puberty in beef heifers. Theriogenology, 52, 67-79.

Jones, E. J., Armstrong, J. D. \& Harvey, R. W. 1991. Changes in metabolites, metabolic hormones, and luteinizing hormone before puberty in Angus, Braford, Charolais, and Simmental heifers. Journal of Animal Science, 69, 1607-1615.

Kinder, J. E., Bergfeld, E. G., Wehrman, M. E., Peters, K. E. \& Kojima, F. N. 1995. Endocrine basis for puberty in heifers and ewes. Journal of Reproduction and Fertility, 49, 393-407.

Kinder, J. E., Day, M. \& Kittok, R. 1987. Endocrine regulation of puberty in cows and ewes. Journal of reproduction and fertility. Supplement, 34, 167-186.

Lamb, G. C., Larson, J. E., Geary, T. W., Stevenson, J. S., Johnson, S. K., Day, M. L., Ansotegui, R. P., Kesler, D. J., DeJarnette, J. M. \& Landblom, D. G. 2006. Synchronization of estrus and artificial insemination in replacement beef heifers using gonadotropinreleasing hormone, prostaglandin $\mathrm{F} 2 \alpha$, and progesterone 1. Journal of Animal Science, 84, 3000-3009.

Lebrethon, M.-C., Vandersmissen, E., Gerard, A., Parent, A.-S., Junien, J. L. \& Bourguignon, J.P. 2000. In vitro stimulation of the prepubertal rat gonadotropin-releasing hormone pulse generator by leptin and neuropeptide $\mathrm{Y}$ through distinct mechanisms. Endocrinology, 141, 1464-1469.

Machado, P. F. A., Bergmann, J. A. G., Pereira, J. C. C. \& Silva, M. A. 2001. Predição da taxa de gestação de novilhas da raça Nelore acasaladas 
com um ano de idade. Arquivo Brasileiro de Medicina Veterinária e Zootecnia, 53, 1-10.

Marson, E. P., Guimarães, J. D. \& Miranda Neto, T. 2004. Puberdade e maturidade sexual em novilhas de corte. Revista Brasileira de Reprodução Animal, 28, 3-12.

Medina, C. L., Nagatani, S., Darling, T. A., Tsukamura, H., Maeda, K. i. \& Foster, D. L. 1998. Glucose availability modulates the timing of the luteinizing hormone surge in the ewe. Journal of Neuroendocrinology, 10, 785792.

Moran, C., Quirke, J. F. \& Roche, J. F. 1989. Puberty in heifers: a review. Animal Reproduction Science, 18, 167-182.

Nakada, K., Moriyoshi, M., Nakao, T., Watanabe, G. \& Taya, K. 2000. Changes in concentrations of plasma immunoreactive follicle-stimulating hormone, luteinizing hormone, estradiol-17 $\beta$, testosterone, progesterone, and inhibin in heifers from birth to puberty. Domestic Animal Endocrinology, 18, 57-69.

Owens, F. N., Dubeski, P. \& Hanson, C. F. 1993. Factors that alter the growth and development of ruminants. Journal of Animal Science, 71, 3138-3150.

Patterson, D. J., Perry, R. C., Kiracofe, G. H., Bellows, R. A., Staigmiller, R. B. \& Corah, L. R. 1992. Management considerations in heifer development and puberty. Journal of Animal Science, 70, 4018-4035.

Patterson, D. J., Wood, S. L. \& Randle, R. F. 2000. Procedures that support reproductive management of replacement beef heifers1. Journal of Animal Science, 77, 1-15.

Pereira, E. S., Pimentel, P. G., Queiroz, A. C. \& Mizubuti, I. Y. 2010. Novilhas leiteiras. Graphiti Gráfica e Editora Ltda, Fortaleza, Ceará.

Pfeifer, L. F. M., Siqueira, L. G., Mapletoft, R. J., Kastelic, J. P., Adams, G. P., Colazo, M. G. \& Singh, J. 2009. Effects of exogenous progesterone and cloprostenol on ovarian follicular development and first ovulation in prepubertal heifers. Theriogenology, 72, 10541064.

Prado, L. S., Queiroz, G. R., Junior Celso, K., Junior, F. A. B. \& Cunha, C. L. F. C. 2015. Avaliação da taxa de concepção em novilhas submetidas a inseminação artificial em tempo fixo após um protocolo de pré-sincronização com progesterona. Journal of Health Sciences, 11, 37-39.

Prolo, P., Wong, M.-L. \& Licinio, J. 1998. Leptin. The International Journal of Biochemistry \& Cell Biology, 30, 1285-1290.

Rawlings, N. C., Evans, A. C. O., Honaramooz, A. \& Bartlewski, P. M. 2003. Antral follicle growth and endocrine changes in prepubertal cattle, sheep and goats. Animal Reproduction Science, 78, 259-270.

Robinson, J. J., Ashworth, C. J., Rooke, J. A., Mitchell, L. M. \& McEvoy, T. G. 2006. Nutrition and fertility in ruminant livestock. Animal Feed Science and Technology, 126, 259-276.

Rodrigues, H. D., Kinder, J. E. \& Fitzpatrick, L. A. 2002. Estradiol regulation of luteinizing hormone secretion in heifers of two breed types that reach puberty at different ages. Biology of Reproduction, 66, 603-609.

Sá Filho, M. F., Nasser, L. F. T., Penteado, L., Prestes, R., Marques, M. O., Freitas, B. G., Monteiro, B. M., Ferreira, R. M., Gimenes, L. U. \& Baruselli, P. S. 2015. Impact of progesterone and estradiol treatment before the onset of the breeding period on reproductive performance of Bos indicus beef heifers. Animal Reproduction Science, 160, 30-39.

Sá Filho, O. G., Valarelli, R. L., Peres, R. F. G., Hoe, F. G. H., Meneghetti, M. \& Vasconcelos, J. L. M. 2007. Avaliação do uso do acetato de melengestrol (MGA® Premix) em vacas de corte. A Hora Veterinária, 27, 1-5.

Schams, D., Schallenberger, E., Gombe, S. \& Karg, H. 1981. Endocrine patterns associated with puberty in male and female cattle. Journal of Reproduction and Fertility, 30, 103-110.

Semmelmann, C. E. N., Lobato, J. F. P. \& Rocha, M. G. 2001. Efeito de sistemas de alimentação no ganho de peso e desempenho reprodutivo de novilhas Nelore acasaladas aos 17/18 meses. Revista Brasileira de Zootecnia, 30, 835-843.

Silva, J. A., Van Melis, M. H., Eler, J. P. \& Ferraz, J. B. S. 2003. Estimação de parâmetros genéticos para probabilidade de prenhez aos 14 meses e altura na garupa em bovinos da raça Nelore. Revista Brasileira de Zootecnia, 32, 1141-1146.

Silva, L. F. P. E., Carvalho, M. V. \& DinizMagalhães, J. 2009. Crescimento e puberdade de novilhas zebuínas. In: Santos, M. V., Rennó, F. P., Silva, L. F. P. \& R., A. (eds.) Novos 
desafios da pesquisa em nutrição e produção animal. Editora 5D, Pirassununga.

Steiner, R. A., Cameron, J. L., Mcneill, T. H., Clifton, D. K. \& Bremner, W. J. 1983. Reproductive neuroendocrinology of the aging male. In: Norman, R. L. (ed.) Academic Press, New York. New York: Academic Press, New York, USA.

Stygar, A. H., Kristensen, A. R. \& Makulska, J. 2014. Optimal management of replacement heifers in a beef herd: A model for simultaneous optimization of rearing and breeding decisions. Journal of Animal Science, 92, 3636-3649.

Tauck, S. A., Wilkinson, J. R. C., Olsen, J. R., Janitell, J. N. \& Berardinelli, J. G. 2007. Comparison of controlled internal drug release device and melengesterol acetate as progestin sources in an estrous synchronization protocol for beef heifers. Theriogenology, 68, 162-167.

Vaiciunas, A., Coutinho, L. L., Meirelles, F. V., Pires, A. V. \& Silva, L. F. P. 2008. Leptin and hypothalamic gene expression in early-and late-maturing Bos indicus Nellore heifers. Genetics and Molecular Biology, 31, 657-664.

Webb, R., Garnsworthy, P., Gong, J.-G. \& Armstrong, D. 2004. Control of follicular growth: local interactions and nutritional influences. Journal of Animal Science, 82, E63-E74.

Webb, R., Nicholas, B., Gong, J. G., Campbell, B. K., Gutierrez, C. G., Garverick, H. A. \& Armstrong, D. G. 2003. Mechanisms regulating follicular development and selection of the dominant follicle. Reproduction, 61, 7190.

Wolfe, M. W., Stumpf, T. T., Wolfe, P. L., Day, M. L., Koch, R. M. \& Kinder, J. E. 1990. Effect of selection for growth traits on age and weight at puberty in bovine females. Journal of Animal Science, 68, 1595-1602.

Yavas, Y. W. J. S. \& Walton, J. S. 2000. Postpartum acyclicity in suckled beef cows: a review. Theriogenology, 54, 25-55.

Yelich, J. V., Wettemann, R. P., Marston, T. T. \& Spicer, L. J. 1996. Luteinizing hormone, growth hormone, insulin-like growth factor-I, insulin and metabolites before puberty in heifers fed to gain at two rates. Domestic Animal Endocrinology, 13, 325-338.

Zervoudakis, J. T., Cecon, P. R., Paulino, M. F., Valadares Filho, S. d. C., Lana, R. d. P. \& Detmann, E. 2002. Desempenho de novilhas mestiças e parâmetros ruminais em novilhos, suplementados durante o período das águas. Revista Brasileira de Zootecnia, 31, 10501058.

Article History:

Received 18 January 2018

Accepted 3 March 2018

Available online 6 April 2018

License information: This is an open-access article distributed under the terms of the Creative Commons Attribution License 4.0, which permits unrestricted use, distribution, and reproduction in any medium, provided the original work is properly cited. 